\title{
SYNTHESIS AND PROPERTIES OF NANOPHASE MATERIALS
}

\author{
Richard W. Siegel \\ Materials Science Division \\ Argonne National Laboratory \\ Argonne, IL 60439
}

$\mathrm{ANL} / \mathrm{MSD} / \mathrm{CP}--76872$

DE93 011757

\section{March 1993}

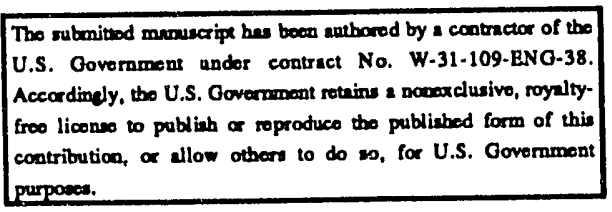

\section{DISCLAIMER}

This report was prepared as an account of work sponsored by an agency of the United States Government. Neither the United States Government nor any agency thereof, nor any of their employees, makes any warranty, express or implied, or assumes any legal liability or responsibility for the accuracy, completeness, or usefulness of any information, apparatus, product, or process disclosed, or represents that its use would not infringe privately owned rights. Reference herein to any specific commercial product, process, or service by trade name, trademark, manufacturer, or otherwise does not necessarily constitute or imply its endorsement, recommendation, or favoring by the United States Government or any agency thereof. The views and opinions of authors expressed herein do not necessarily state or reflect those of the United States Government or any agency thereof.

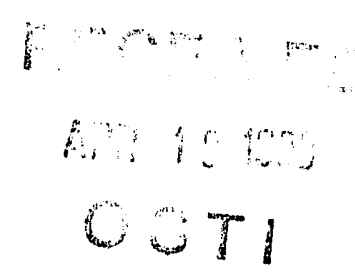

INVITED keynote paper presented at the Symposium on Nanophase Materials, E-MRS Meeting, Strasbourg, France 3-5 November 1992; to be published in Materials Science \& Engineering A (1993).

*Work supported by the U. S. Department of Energy, BES-Materials Sciences, under Contract W-31-109-Eng-38. 
Invited keynote paper presented at the Symposium on Nanophase Materials, E-MRS Meeting, Strasbourg, France, 3-5 November 1992; to be published in Materials Science \& Engineering A (1993).

\title{
Synthesis and properties of nanophase materials
}

\author{
Richard W. Siegel \\ Materials Science Division, Argonne National Laboratory, Argonne, Illinois 60439 USA
}

(Received February 12, 1993)

\begin{abstract}
Nanophase materials, with their grain sizes or phase dimensions in the nanometer size regime, are now being produced by a wide variety of synthesis and processing methods. The interest in these new ultrafine-grained materials results primarily from the special nature of their various physical, chemical, and mechanical properties and the possibilities to control these properties during the synthesis and subsequent processing procedures. Since it is now becoming increasingly apparent that their properties can be engineered effectively during synthesis and processing, and that they can also be produced in quantity, nanophase materials should have considerable potential for technological development in a variety of applications. Some of the recent research on nanophase materials related to their synthesis and properties is briefly reviewed and the future potential of these new materials is considered.
\end{abstract}




\section{Introduction}

Nanophase materials are three-dimensionally modulated, synthetic materials with average grain, phase, or other structural domain sizes below $100 \mathrm{~nm}$. Interest in them has increased rapidly during the past several years with successive demonstrations that their properties are different from and frequently superior to those of conventional materials that have phase or grain structures on much coarser size scales [1]. These materials can be synthesized by the assembly of physically or chemically derived atom clusters or by means of mechanical deformation processes. Each of these methods has its advantages, but in-situ consolidation of gas-condensed clusters [2, 3] appears to be fundamentally the most flexible method presently available.

It is important to understand that nanophase materials are only one of the much broader class of nanostructured materials artificially synthesized with microstructures modulated in zero to three dimensions on length scales less than $100 \mathrm{~nm}$ that it has become possible to create over the past few years. The various types of nanostructured materials share three common features, atomic domains spatially confined to less than $100 \mathrm{~nm}$, significant atom fractions associated with interfacial environments, and interactions between their constituent domains. It is these three features that largely determine their unique properties. These materials can therefore be loosely classified [4] according to their modulation dimensionality: zero-dimensionality atom clusters (with any aspect ratio from one to infinity, including equiaxed clusters as well as filaments or tubules); one-dimensionally modulated multilayers; two-dimensionally modulated ultrafine-grained overlayers and buried layers; and three-dimensionally modulated cluster assemblies, including nanophase materials.

Nanophase materials, through control of the sizes of the constituent structural components of which they are synthesized, can incorporate a number of size-related effects in condensed matter ranging from electronic effects (sc-called "quantum size effects") caused by spatial confinement of delocalized valence electrons and altered cooperative ("many body") atom phenomena, such as lattice vibrations or melting, to the suppression of such lattice-defect mechanisms as dislocation generation and migration in confined grain sizes. It appears likely that the emerging possibilities to 
artificially assemble size-selected entities, such as atom clusters for example, into new materials with unique or improved properties may have a revolutionary impact upon our ability to engineer materials with controlled optical, electronic, mechanical, and chemical properties for a wide variety of useful technological applications in the future.

The present paper is intended as a brief review of some of the ways in which nanophase materials can be synthesized and how the controlled synthesis and processing of these new materials can lead to prescribed size dependent properties. More extensive reviews have recently appeared elsewhere [5-7]. Emphasis here will be placed on the special opportunities presented by our ability to create nanophase materials assemiled from atom clusters of metals and ceramics synthesized by means of the gas-conderisation method $[3,6,8]$, since this method appears to be the most generally applicable of the presently available avenues for producing nanophase materials, and thus appears to have very broad technological potential.

\section{Nanophase material synthesis}

\subsection{Cluster assembly}

There are a wide variety of chemical and physical methods for the production of atom clusters or ultrafine powders that can be assembled to synthesize nanophase materials. One of the traditional methods for synthesizing ultrafine powders or colloidal suspensions has been chemical precipitation. Several of these methods, including sol-gel synthesis $[9,10]$ and the inverse micelle method [11] for example, have been successfully applied to the synthesis of nanometer sized clusters with narrow size distributions. Additional references to the variety of interesting methods available can be found elsewhere $[1,2,12-16]$ and in the pages of these Proceedings. Invariably, in each of these chemical precipitation methods, the synthesized clusters are coated by residual surface layers (often intentionally introduced to cap the clusters at a given size or to keep them from agglomerating and forming large pores) from the solutions in which they are formed. These surface layers create few, if any, problems in the study of isolated clusters. However, if the 
clusters are to be assembled into bulk solids, then these surface layers can become contaminants in the grain boundaries of the cluster-consolidated material, and processing and properties can be adversely affected. Such potential problems can be avoided in the gas-condensation method for synthesizing nanophase materials.

The study of the gas condensation of ultrafine particles or atom clusters has had a rather long history stretching back to the formation and use of 'smokes', such as carbon or bismuth 'blacks', for a variety of applications [17]. Scientific research into the controlled production of ultrafine particles by means of the gas-condensation method has been more recent $[8,18-20]$. The application of these ideas in recent years $[3,21-24]$ to the synthesis of a variety of nanophase metals and ceramics has built upon this broad scientific and technological base and the previously assembled knowledge of powder metallurgy and ceramics.

The generation of atom clusters via gas condensation proceeds by evaporating a precursor material, either an element or compound, in a gas maintained at a low pressure, usually well below one atmosphere in an apparatus [25] such as that shown in Fig. 1. The evaporated atoms or molecules lose energy via collisions with the gas atoms or molecules and undergo a homogeneous condensation to form atom clusters in the highly supersaturated vicinity of the precursor source. In order to maintain small cluster sizes, by minimizing further atom or molecule accretion and cluter-cluster coalescence, the clusters once nucleated must be removed rapidly from the region of high supersaturation. Since the clusters are already entrained in the condensing gas, this is readily accomplished by setting up conditions for moving this gas. Such gas motion has generally been driven by natural convection under the combined action of gravity and the temperature difference between the precursor source and a cooled thermophoretic cluster collection surface. However, a forced gas flow can be used instead of natural convective flow, which should be able to yield significant advantages in terms of both cluster size control and process efficiency.

There are only three fundamental rates, which function relative to one another, that essentially control the formation of the atom clusters in the gas-condensation process [6]. They are (1) the rate of supply of atoms to the region of supersaturation where condensation occurs, (2) the rate of energy removal from the hot atoms via the condensing medium, the gas, and (3) the rate of removal of the clusters once nucleated from the supersaturation region. Other factors can also 
affect the clusters finally collected, particularly those that result in significant cluster-cluster coalescence, but these three rates represent the core of the process. Accordingly, the smallest cluster sizes for a given precursor are obtained for a low evaporation rate and condensation in a low pressure of a light inert gas, such as He. These conditions lead to a lower supersaturation of precursor atoms in the gas, slower removal of energy from the evaporated atoms (via the lighter gas atoms at lower pressure), and more rapid convective gas flow owing also to the lower gas pressure. The rapid gas flow is significant, since it guarantees a shorter dwell time of the gas-entrained condensed clusters in the supersaturated region in which, if they remained, they would grow further.

The apparatus shown in Fig. 1, which uses such a process for the synthesis of nanophase materials via the in situ consolidation of gas-condensed clusters, consists of an ultrahigh-vacuum (UHV) system fitted with two resistively-heated evaporation sources, a cluster collection device (liquid-nitrogen filled cold finger) and scraper assembly, and in situ compaction devices for consolidating the powders produced and collected in the chamber. Before making the powders, the UHV system is first evacuated by means of a turbomolecular pump to below $10^{-5} \mathrm{~Pa}$ and then back-filled with a controlled high-purity gas atmosphere at pressures of about a few hundred $\mathrm{Pa}$. For producing metal powders this is usually an inert gas, such as $\mathrm{He}$, but it can alternatively be a reactive gas or gas mixture if, for example, clusters of a ceramic compound are desired.

The clusters that are collected via thermophoresis on the surface of the cold finger form very open, fractal structures. They are held on the collector surface rather weakly, via Van der Waals type forces, and are easily removed from this collection surface by means of a Teflon scraper. Upon removal, the clusters fall like 'snow' from the surface and are funneled into a set of compaction devices (see Fig. 1) capable of consolidation pressures up to about 1-2 GPa, in which the nanophase samples are formed at room temperature, or at elevated temperatures if needed. The pellets formed in this conventional research apparatus are typically about $9 \mathrm{~mm}$ in diameter and 0.2 to $1.0 \mathrm{~mm}$ thick, depending upon the amount of material made (usually a few hundred milligrams) and the experiments to be performed. The sizes of these samples have been more a matter of laboratory convenience than any real limitation of the gas-condensation method itself. All of the fundamental rates involved in the cluster synthesis can be significantly increased above those 
presently in use in the laboratory and scaled up production rates leading to samples with greatly increased sizes are clearly feasible. The scraping and consolidation are performed under UHV ccnditions after removal of the inert or reactive gases from the chamber, in order to maximize the cleanliness of the particle surfaces and the interfaces that are subsequently formed. Also, any possibility of trapping remnants of these gases in the nanophase compact is minimized by consolidation in vacuum. It should be noted in this regard that the total surface area of the nanophase powders produced in a given run is su great that, for a residual gas pressure of less than $10^{-5} \mathrm{~Pa}$ in a volume the size of the UHV chamber used, little gas contamination of the cluster surfaces would be expected.

Since the as-collected gas-condensed clusters are generally aggregated in rather open fractal arrays $[18,19]$, their consolidation at pressures of $1-2 \mathrm{GPa}$ is easily accomplished, even at room temperature. The difficulties in consolidating the hard equiaxed agglomerates of fine powders resulting from conventional wet chemistry synthesis routes are mostly avoided. The sample densities resulting from cluster consolidation at room temprature have ranged up to about $97 \%$ of theoretical for nanophase metals and up to about $75-85 \%$ of theoretical for nanophase oxide ceramics. The remaining "green-state" porosity represents (at least in part) a manifestation of powder agglomeration leading to void-like flaws. Fortunately, it appears that these can be removed by means of cluster consolidation at elevated temperatures and pressures without significant attendant grain growth.

Most of the atom clusters assembled into nanophase materials to date have been generated from Joule-heated evaporation sources. However, such sources have limitations that need not be suffered, since a wide variety of other sources are also available. The primary limitations are source-precursor incompatability, temperature range, uniformity and control, and dissimilar evaporation rates for different constituents in an alloy or compound precursor. Each of these limitations can be avoided by a host of alternative sources that have been developed over the years of ultrafine particle research [20], but which are only now beginning to enter the field of nanophase materials synthesis. Among other sources for bringing atom supersaturations into a condensing gas medium that have been successfully used to produce clusters or ultrafine particles are Joule-heated ovens [26-28], sputtering [29-33], electron-beam heating [34-37], laser ablation [38], 
and plasma methods $[39,40]$. It should be clear that this wide variety of evaporation methods will allow for greatly increased flexibility in the use of refractory or reactive precursors for clusters and will be especially useful as we begin in the future to synthesize technological quantities of more complex multicomponent or composite nanophase materials.

\subsection{Mechanical attrition}

Nanophase structures can also be generated by means of severe mechanical deformation. Mechanical attrition produces its nanostructures, not by cluster assembly, but by means of the structural decomposition of coarser-grained structures induced by the high stored energy density from the mechanical deformation. It appears that nanometer size grains nucleate within the shear bands of heavily deformed materials converting a coarse-grained structure to nanophase. The heavy deformation is usually effected by means of high-energy ball milling [41-43], but can as well result from surface wear phenomena [44] and other methods for introducing high densities of deformation, such as the high-energy shear process and other manifestations of severe deformation described in these Proceedings. In mechanical attrition, therefore, the individual grains are never isolated clusters and much of the synthesis and processing flexibility is lost relative to the gas-condensation method. Nevertheless, ultrafine grain sizes can be readily accessed by this rather straightforward method, as shown in Fig 3. High-energy ball milling is capable of producing commercial quantities of material, albeit with some contamination problems from the sources of mechanical work, but for those applications in which careful control of purity or grain morphology are not important, and for which the desired properties are accessible in the mechanically attrited nanostructures, it can be a useful source of these materials. The variation with grain size as a function of ball-milling time in Pd [45] shown in Fig. 3 clearly shows that grain sizes down into the nanometer regime can be accessed, although it is more easily accomplished in relatively harder materials. Mechanical attrition exercised at low temperatures ("cryomilling") can extend the range of applicability, as shown by Luton et al. [46] in their work on dispersion-strengthened Al.

The predominant feature of nanophase materials synthesized by any method is their ultrafine 
grain size below $100 \mathrm{~nm}$ and, hence, the large fraction of their atoms that reside in grain boundaries or interfaces. For example, as indicated in Fig. 4, a nanophase material with a $5 \mathrm{~nm}$ average grain size will have from about 27 to $49 \%$ of its atoms associated with grain boundaries, assuming a simple grain boundary picture and an average grain boundary thickness of about 0.5 to $1.0 \mathrm{~nm}$ (ca. 2-4 nearest-neighbor distances). This percentage falls to about $14-27 \%$ for a $10 \mathrm{~nm}$ grain size, but is as low as $1-3 \%$ for a $100 \mathrm{~nm}$ grain size. The interface volume fraction is, of course, essentially negligible for conventional grain sizes of $1 \mu \mathrm{m}$ and above. The simple model upon which Fig. 4 is based assumes only that the grain volumes scale as a length cubed and that the grain boundary volume includes the junctions between and among their boundaries [47]. The properties of nanostructured materials are thus expected to be strongly influenced by both their small (and hence confined) grain sizes and the nature (atomic and electronic structure) of their internal boundaries, simply because of the very large number density of these interfaces.

Considerable effort has gone into the elucidation of the structure of nanophase grain boundaries [5, 48, 49]. Investigations of nanophase $\mathrm{TiO}_{2}$ by Raman spectroscopy [50-52] and of nanophase Pd by high resolution, transmission electron microscopy $[53,54]$ indicate that the grain boundary structures in these materials are essentially low energy configurations that are rather similar to those in coarser grained, conventional materials [55]. The nanophase grain boundaries, as those shown in Fig. 5, contain short-range ordered structural units representative of the bulk material and distortions that are localized to about $\pm 0.2 \mathrm{~nm}$ on either side of the grain boundary plane. These conclusions are also consistent with the results from complementary small-angle neutron scattering measurements [56-58], and with the expectations for conventional high angle grain boundaries from condensed matter theory $[59,60]$. Whether or not there are indeed some local structural deviations in nanophase boundaries compared with conventional scale grain boundaries is still an open question [5,49], although it is becoming clear that significant lattice strains are a reality in nanophase materials as prepared by both cluster-consolidation and machanical-attrition methods $[61,62]$. However, no firm experimental or theoretical evidence presently exists which indicates that the structures of nanophase grain boundaries are actually different than their coarse-grained counterparts. 


\section{Material properties}

Nanophase materials have a variety of properties that are considerably different and improved in comparison with those of conventional coarser-grained structures. These result from the impact of various combinations of the three important aspects (size, composition, and interfaces) of their nature. A few examples will be presented here to try and give a sense of how the interplay among these aspects can significantly alter some useful technological properties of these materials. A number of other examples can be found in recent reviews cited previously [e.g., 5, 7] and in these Proceedings.

The chemical reactivity of nanophase materials, with their high surface areas compared to conventional materials, can be rather striking. Since gas-condensed, high-surface-area clusters can be assembled via consolidation in the method described in this paper, there can be an excellent degree of control over the total available surface area in these self-supported ensembles. Also, composition control can be readily achieved [51,52]. Recently completed measurements [63] of the decomposition of $\mathrm{H}_{2} \mathrm{~S}$ over lightly consolidated nanophase $\mathrm{TiO}_{2}$ at $500^{\circ} \mathrm{C}$ demonstrate the enhanced chemical reactivity of nanophase materials rather well. Figure 6 shows the catalytic reaction rate for $\mathrm{S}$ removal from $\mathrm{H}_{2} \mathrm{~S}$ via dissociative adsorption for nanophase $\mathrm{TiO}_{2}$ (rutile) compared with that for a number of other commercially available forms of $\mathrm{TiO}_{2}$ having either the rutile or anatase structure. It can be seen that the nanophase sample was far more reactive than any of the other samples tested, both initially and also after extended exposure to the $\mathrm{H}_{2} \mathrm{~S}$. Indeed, only the nanophase titania demonstrated a non-zero reaction rate for sulphur removal after $7 \mathrm{~h}$. This greatly enhanced and sustainable activity was shown to result from a combination of unique and controllable features of the nanophase material, its high surface area combined with its rutile structure and its oxygen deficient composition.

Quite limited research has been carried out so far on the physical properties of cluster-assembled nanophase materials. However there appear to be interesting prospects, based upon what little has been accomplished and on the expectations for confined systems of atoms in which the sizes of constituent domains fall below the critical length scales pertinent to a given 
property. Figure 7 shows one example of how the ability to control the porosity in the synthesis of nanophase ceramics will apparently lead to some rather interesting optical applications in the near future. It was recently demonstrated [64] that the oxidation step in the synthesis of cluster-consolidated nanophase $\mathrm{Y}_{2} \mathrm{O}_{3}$ can be so controlled that the resulting "green-state" porosity of $25-35 \%$ has a size distribution sufficiently small and narrow that the as-consolidated material is effectively transparent. A more recent demonstration of this processing control is shown in Fig. 7. The ability to thus reduce the size of the porosity in such material to well below the wavelengths of visible or other radiation, coupled with the possibilities for efficient doping of these materials cited previously, should lead to a variety of interesting optical properties and related applications.

The predominant mechanical property change resulting from reducing the grain sizes of nanophase metals is the significant increase in their strength $[61,65,66]$. Figure 8 shows microhardness and yield-stress results for several samples of nanophase Cu compared with results for coarser-grained samples. The smallest grain size $(6 \mathrm{~nm})$ sample is seen to exhibit about a $500 \%$ increase in microhardness over an annealed coarser-grained (ca. $50 \mu \mathrm{m}$ ) sample. Nanophase Pd samples with 5-10 nm grain sizes have also been observed to exhibit up to about a $500 \%$ increase in hardness over coarser-grained (ca. $100 \mu \mathrm{m}$ ) samples [65], with concomitant increases in their yield stress as well. The common strengthening behavior found in nanophase $\mathrm{Cu}$ and $\mathrm{Pd}$ indicates that this response is generic to nanophase metals, at least those with a fcc structure. The likelihood that such mechanical behavior is more broadly generic to nanophase metals is indicated by the observations that nanophase metals and alloys produced via mechanical attrition also exhibit significantly enhanced strength. For example, Koch and coworkers [67, 68] have found hardness increases by a factor of about 4 to 5 in nanophase Fe, but only by a factor of about 1.2 in nanophase $\mathrm{Nb}_{3} \mathrm{Sn}$, when the grain size drops from $100 \mathrm{~nm}$ to $6 \mathrm{~nm}$.

The increased strength observed in ultrafine-grained nanophase metals, although apparently analogous to conventional Hall-Petch strengthening observed with decreasing grain size in coarser grained metals, must result from fundamentally different mechanisms. It can be expected that as nanophase grain sizes decrease and fall below the critical length scale for a given mechanism to operate, the associated property will be significantly changed. The grain sizes in the nanophase metals considered here are smaller than the necessary critical bowing lengths for Frank-Read 
dislocation sources to operate at the stresses involved and smaller also than the normal spacings between dislocations in a pile-up. It is therefore clear that an adequate description of the mechanisms responsible for the increased strength observed in nanophase metals will need to accommodate to the ultrafine grain-size scale in these materials. As this scale is reduced, and conventional dislocation generation and migration become increasingly difficult, it is apparent that the energetic hierarchy of microscopic deformation mechanisms will become successively accessed. Thus, easier mechanisms (such as dislocation generation from Frank-Read sources) will become frozen out at sufficiently small grain sizes and more energetically costly mechanisms will become necessary to effect deformation. Hence, grain confinement appears to be the dominant cause for the increased strength of nanophase metals. An additional contribution to the observed strengthening may be the elastic strain accommodation [61] resulting from cluster consolidation.

Also in the area of mechanical behavior, it has been observed that nanophase ceramics are easily formed $[23,69-71]$ and nanoindenter measurements on nanophase $\mathrm{TiO}_{2}[72]$ and $\mathrm{ZnO}$ [73] have recently demonstrated that a dramatic increase of strain rate sensitivity occurs with decreasing grain size. Since this strong grain-size dependence is found for sets of samples in which the porosity is changing very little, it appears that this increased tendency toward ductility is an intrinsic grain-size dependent property of these ultrafine-grained ceramics. The strain rate sensitivity values at the smallest grain sizes yet investigated $\left(12 \mathrm{~nm}\right.$ in nanophase $\mathrm{TiO}_{2}$ and $7 \mathrm{~nm}$ in $\mathrm{ZnO}$ ) thus indicate ductile behavior of these nanophase ceramics, as well as a significant potential for increased ductility at even smaller grain sizes and elevated temperatures. The enhanced strain rate sensitivity at room temperature found in the nanophase ceramics $\mathrm{TiO}_{2}$ and $\mathrm{ZnO}$ appears to result from increased grain boundary sliding in this material, aided by the presence of porosity, ultrafine grain size, and probably rapid short-range diffusion as well, although this mechanism is yet to be demonstrated. This behavior appears therefore to be dominated by the presence of the numerous interfaces in these materials and the very short diffusion distances involved in effecting the necessary atomic healing of incipient cracks for grain boundary sliding to progress at the strain rates utilized without fracturing the sample. Extrapolating from this apparently generic behavior, une can expect that grain boundary sliding mechanisms, accompanied by short-range diffusion assisted healing events, would be expected to increasingly dominate the deformation of nanophase 
materials at sufficiently small grain sizes. Enhanced forming and even superplasticity in a wide range of nanophase materials, including intermetallic compounds, ceramics, and semiconductors might become a reality. Consequently, increased opportunities for high deformation or superplastic near-net-shape forming of a very wide range of even conventionally rather brittle and difficult to form materials could result.

\section{Conclusions and prospects}

Considerable opportunities now exist for synthesizing nanophase materials with a variety of new architectures at nanometer length scales from atomic or molecular precursors via the assembly of atom clusters and $y$ the many other techniques now becoming available. However, the real future of nanophase materials, and other nanostructures as well, will depend upon our ability to significantly change for the better the properties of materials by artificially structuring them on these nanometer length scales and upon developing economic and environmentally responsible methods for producing these materials in commercially viable quantities. Based upon the limited knowledge that has already been accumulated, the future appears to hold great promise for technological applications of nanophase materials, but much work remains to be done.

The examples presented in Sec. 3 and those that can be found in these Proceedings have demonstrated that, even in our crude initial attempts to change and control the properties of materials via nanostructuring, it is already possible to dramatically alter a variety of technologically important properties of materials in this manner. Since cluster "building blocks" can even now be assembled with some modicum of control over the porosity in the nanophase compact and the composition and defect structure of the material, significant positive effects on both the chemical reactivity of a self-supported nanophase 'catalyst' and the optical transparancy of a nanophase ceramic 'window' can result. It is also apparent that the strength of normally very ductile pure metals can be significantly increased simply by reducing their grain sizes into the range where dislocation generation and migration becomes confiner and difficult. On the hand, normally very brittle oxide ceramics can be rendered more ductile and formable by reducing their grain sizes into 
the range where grain boundary sliding becomes facilitated by the high number density of internal interfaces and the rapid atomic diffusion therein. Such examples suggest that even more exciting opportunities may be available as we learn to assemble more sophisticated multifunctional composite nanostructured materials in the future for prescribed applications.

\section{Acknowledgements}

This work was supported by the U.S. Department of Energy, BES-Materials Sciences, under Contract W-31-109-Eng-38. 


\section{References}

1. B. H. Kear, L. E. Cross, J. E. Keem, R. W. Siegel, F. Spaepen, K. C. Taylor, E. L. Thomas, and K.-N. Tu, Research Opportunities for Materials with Ultrafine Microstructures (National Academy, Washington, DC, 1989), Vol. NMAB-454.

2. R. P. Andres, R. S. Averback, W. L. Brown, L. E. Brus, W. A. Goddard, III, A. Kaldor, S. G. Louie, M. Moskovits, P. S. Peercy, S. J. Riley, R. W. Siegel, F. Spaepen, and Y. Wang, J. Mater. Res. 4, 704 (1989).

3. H. Gleiter, in Deformation of Polycrystals: Mechanisms and Microstructures, N. Hansen et al., eds. (Ris $\varnothing$ National Laboratory, Roskilde, 1981) p. 15.

4. R. W. Siegel, Nanostructured Mater. 3, 1 (1993).

5. H. Gleiter, Progress in Materials Science 33, 223 (1989).

6. R. W. Siegel, in Materials Science and Technology, Vol. 15, R. W. Cahn, ed.(VCH, Weinheim, 1991) p. 583.

7. R. W. Siegel, in Mechanical Properties and Deformation Behavior of Materials Having Ultra-Fine Microstructures, M. A. Nastasi et al., eds. (Kluwer, Dordrecht, 1993) in press.

8. C. G. Granqvist and R. A. Buhrman, J. Appl. Phys. 47, 2200 (1976).

9. L. L. Hench and D. R. Ulrich, Science of Chemical Processing (Wiley, New York, 1986).

10. L. C. Klein, Ann. Rev. Mater. Sci. 15, 227 (1985).

11. M. L. Steigerwald and L. E. Brus, Ann. Rev. Mater. Sci. 19, 471 (1991).

12. I. A. Aksay, G. L. McVay, and D. R. Ulrich, eds., Processing Science of Advanced Ceramics, Mater. Res. Soc. Symp. Proc. 155 (1989).

13. P. C. Rieke, P. D. Calvert, and M. Alper, eds., Materials Synthesis Utilizing Biological Processes, Mater. Res. Soc. Symp. Proc. 174 (1990).

14. R. S. Averback, D. L. Nelson, and J. Bernholc, eds., Clusters and Cluster-Assembled Materials, Mater. Res. Soc. Symp. Proc. 206 (1991). 
15. G. M. Whitesides, J. P. Mathias, and C. T. Seto, Science 254, 1312 (1991).

16. A. H. Heuer, D. J. Fink, V. J. Laraia, J. L. Arias, P. D. Calvert, K. Kendall, G. L. Messing, J. Blackwell, P. C. Rieke, D. H. Thompson, A. P. Wheeler, A. Veis, and A. I. Caplan, Science 255, 1098 (1992).

17. A. H. Pfund, Rev. Sci. Inst.1, 397 (1930)

18. K. Kimoto, Y. Kamiya, M. Nonoyama, and R. Uyeda, Jpn. J. Appl. Phys. 2, 702 (1963).

19. A. R. Thölén, Acta Metall. 27, 1765 (1979).

20. R. Uyeda, Prog. Mater. Sci. 35, 1 (1991)

11. M. L. Steigerwald and L. E. Brus, Ann. Rev. Mater. Sci. 19, 471 (1991).

21. R. Birringer, U. Herr, and H. Gleiter, Suppl. Trans. Jpn. Tast. Met. 27, 43 (1986).

22. R. W. Siegel and H. Hahn, in Current Trends in the Physics of Materials, $M$. Yussouff, ed. (World Scientific Publ. Co., Singapore, 1987) p. 403.

23. R. W. Siegel, S. Ramasamy, H. Hahn, Z. Li, T. Lu, and R. Gronsky, J. Mater. Res. 3, 1367 (1988).

24. J. A. Eastman, Y. X. Liao, A. Narayanasamy, and R. W. Siegel, Mater. Res. Soc. Symp. Proc. 155, 255 (1989).

25. R. W. Siegel and J. A. Eastman, Mater. Res. Soc. Symp. Proc. 132, 3 (1989).

26. K. Sattler, J. Mühlbach, and E. Recknagel, Phys. Rev. Lett. 45, 821 (1980).

27. K. Sattler, Ultramicroscopy 20, 55 (1986).

28. K. Sattler, Z. Phys. D 3, 223 (1986).

29. H. Oya, T. Ichihashi, and N. Wada, Jpn. J. Appl. Phys. 21, 554 (1982).

30. S. Yatsuya, K. Yamauchi, T. Kamakura, A. Yanagada, H. Wakaiyama, and K. Mihama, Surface Sci. 156, 1011 (1985).

31. S. Yatsuya, T. Kamakura, K. Yamauchi, and K. Mihama, Jpn. J. Appl. Phys., Part 2, 25, L42 (1986).

32. H. Hahn and R. S. Averback, J. Appl. Phys. 67, 1113 (1990).

33. G. M. Chow, R. L. Holtz, A. Pattnaik, A. S. Edelstein, T. E. Schlesinger, and R. C. Cammerata, Appl. Phys. Lett. 56, 1853 (1990).

34. S. Iwama, E. Shichi, and T. Sahashi, Jpn. J. Appl. Phys. 12, 1531 (1973). 
35. S. Iwama, K. Hayakawa, and T. Arizumi, J. Cryst. Growth 56, 265 (1982); ibid. 66, 189 (1984).

36. S. Iwama and K. Hayakawa, Surface Sci. 156, 85 (1985).

37. B. Günther and A. Kumpmann, Nanostructured Mater. 1, 27 (1992).

38. A. Matsunawa and S. Katayama, in Laser Welding, Machining and Materials

Processing, Proc. ICALEO '85, C. Albright, ed. (IFS Publ. Ltd.,1985) p. 205.

39. K. Baba, N. Shohata, and M. Yonezawa, Appl. Phys. Lett. 54, 2309 (1989).

40. M. Uda, Nanostructured Mater. 1, 101 (1992).

41. E. Hellstern, H. J. Fecht, Z. Fu, and W. L. Johnson, J. Appl. Phys. 65, 305 (1989).

42. C. C. Koch, J. S. C. Jang, and S. S. Gross, J. Mater. Res. 4, 557 (1989).

43. H. J. Fecht, E. Hellstern, Z. Fu, and W. L. Johnson, Adv. Powder Metall. 1-2, 111 (1989).

44. S. K. Ganapathi and D. A. Rigney, Scripta Metall. et Mater. 24, 1675 (1990).

45. J. Eckert, J. C. Holzer, C. E. Krill, II, and W. L. Johnson, J. Mater. Res. 7, 1751 (1992); Mater. Res. Soc. Symp. Proc. 238, 745 (1992).

46. M. J. Luton, C. S. Janath, M. M. Disko, S. Matras, and J. Vallone, Mater. Res. Soc. Symp. Proc. 132, 79 (1989).

47. R. W. Siegel, Ann. Rev. Mater. Sci. 21, 559 (1991).

48. R. Birringer and H. Gleiter, in Encyclopedia of Materials Science andEngineering, Suppl. Vol. 1, R. W. Cahn, ed. (Pergamon Press, Oxford, 1988) p. 339.

49. R. W. Siegel, in Materials Interfaces: Atomic-Level Structure and Properties, D. Wolf and S. Yip, eds. (Chapman and Hall, London, 1992) p. 431.

50. C. A. Melendres, A. Narayanasamy, V. A. Maroni, and R. W. Siegel, J. Mater. Res. 4, 1246 (1989).

51. J. C. Parker and R. W. Siegel, J. Mater. Res. 5, 1246 (1990).

52. J. C. Parker and R. W. Siegel, App!. Phys. Lett. 57, 943 (1990).

53. G. J. Thomas, R. W. Siegel, and J. A. Eastman, Mater. Res. Soc. Symp. Proc. 153, 13 (1989).

54. G. J. Thomas, R. W. Siegel, and J. A. Eastman, Scripta Metall. et Mater. 24, 201 (1990).

55. R. W. Siegel and G. J. Thomas, Ultramicroscopy 40, 376 (1992). 
56. J. E. Epperson, R. W. Siegel, J. W. White, T. E. Klippert, A. Narayanasamy, J. A. Eastman, and F. Trouw, Mater. Res. Soc. Symp. Proc. 132, 15 (1989).

57. E. Jorra, H. Franz, J. Peisl, G. Wallner, W. Petry, R. Birringer, H. Gleiter, and T. Haubold, Phil. Mag. B 60, 159 (1989).

58. J. E. Epperson, R. W. Siegel, J. W. White, J. A. Eastman, Y. X. Liao, and A. Narayanasamy, Mater. Res. Soc. Symp. Proc. 166, 87 (1990).

59. S. R. Phillpot, D. Wolf, and S. Yip, MRS Bulletin XV(10), 38 (1990).

60. D. Wolf and J. F. Lutsko, Phys. Rev. Lett. 60, 1170 (1988).

61. G. W. Nieman, J. R. Weertman, and R. W. Siegel, J. Mater. Res. 6, 1012 (1991).

62. R. Valiev, in Mechanical Properties and Deformation Behavior of Materials Having Ultra-Fine Microstructures, M. A. Nastasi et al., eds. (Kluwer, Dordrecht, 1993) in press.

63. D. D. Beck and R. W. Siegel, J. Mater. Res. 7, 2840 (1992).

64. G. Skandan, H. Hahn, and J. C. Parker, Scripta Metall. et Mater. 25, 2389 (1991).

65. G. W. Nieman, J. R. Weertman, and R. W. Siegel, Scripta Metall. 23, 2013 (1989).

66. G. W. Nieman, J. R. Weertman, and R. W. Siegel, Scripta Metall. et Mater. 24, 145 (1990).

67. J. S. C. Jang and C. C. Koch, Scripta Metall. et Mater. 24, 1599 (1990).

68. C. C. Koch and Y. S. Cho, Nanostructured Mater. 1, 207 (1992).

69. J. Karch, R. Birringer, and H. Gleiter, Nature 330, 556 (1987).

70. J. Karch and R. Birringer, Ceramics International 16, 291 (1990).

71. H. Hahn, J. Logas, H. J. Höfler, P. Kurath, and R. S. Averback, Mater. Res. Soc. Symp. Proc. 196, 71 (1990).

72. M. J. Mayo, R. W. Siegel, A. Narayanasamy, and W. D. Nix, J. Mater. Res. 5, 1073 (1990).

73. M. J. Mayo, R. W. Siegel, Y. X. Liao, and W. D. Nix, J. Mater. Res. 7, 973 (1992). 


\section{Figure captions}

Fig. 1. Schematic drawing of a gas-condensation chamber for the synthesis of nanophase materials. Precursor material evaporated from sources A and/or B condenses in the gas and is transported via convection to the liquid-nitrogen filled cold finger. The clusters are then scraped from the cold finger, collected via the funnel, and consolidated first in the low-pressure compaction unit and then in the high-pressure compaction unit, all in vacuum [25].

Fig. 2. Median particle diameter versus pressure of $\mathrm{He}, \mathrm{Ar}$, or $\mathrm{Xe}$ gas for clusters of $\mathrm{Al}$ and $\mathrm{Cu}$ formed via gas-condensation [8]. The straight lines only serve as a guide.

Fig. 3. Average grain size, determined by X-ray line broadening, of Pd as a function of ball-milling time [45].

Fig. 4. Percentage of atoms in grain boundaries of a nanophase material as a function of grain diameter, assuming that the average grain boundary thickness ranges from 0.5 to $1.0 \mathrm{~nm}$ (ca. 2 to 4 atomic planes wide) [47].

Fig. 5. High resolution transmission electron micrograph of a typical area in nanophase Pd [53].

Fig. 6. Reaction rates for $\mathrm{H}_{2} \mathrm{~S}$ decomposition as a function of exposure time at $500^{\circ} \mathrm{C}$ for nanophase $\mathrm{TiO}_{2}$ compared with that from several commercially available $\mathrm{TiO}_{2}$ materials and a reference (Catalyst A: $76 \mathrm{~m}^{2} / \mathrm{g}$ nanophase rutile; B: $61 \mathrm{~m}^{2} / \mathrm{g}$ anatase; C: $2.4 \mathrm{~m}^{2} / \mathrm{g}$ rutile; $\mathrm{D}: 30 \mathrm{~m}^{2} / \mathrm{g}$ anatase; $\mathrm{E}: 20 \mathrm{~m} 2 / \mathrm{g}$ rutile; F: reference alumina) [63].

Fig. 7. Pore size distribution in nanophase $\mathrm{Y}_{2} \mathrm{O}_{3}$ (the powder is shown in the inset transmission electron micrograph) consolidated at room temperature under $136 \mathrm{MPa}$ pressure to a density of about $40 \%$ of the theoretical value. The transparent sample is shown on the axis at about its average grain diameter, 8 nm [courtesy of J. C. Parker, Nanophase Technologies Corporation]. 
Fig. 8. Vickers microhardness $\mathrm{H}_{\mathrm{V}}$ of as-consolidated nanophase $\mathrm{Cu}$ samples, ranging in average grain size d from 6 to $50 \mathrm{~nm}$, compared with similar measurements from an annealed conventional $50 \mu \mathrm{m}$ grain size $\mathrm{Cu}$ sample. The $0.2 \%$ offset yield stress $\sigma_{\mathrm{y}}$ of two nanophase $\mathrm{Cu}$ samples and a coarse-grained sample are also shown as a function of $d^{-1 / 2}[61]$. 


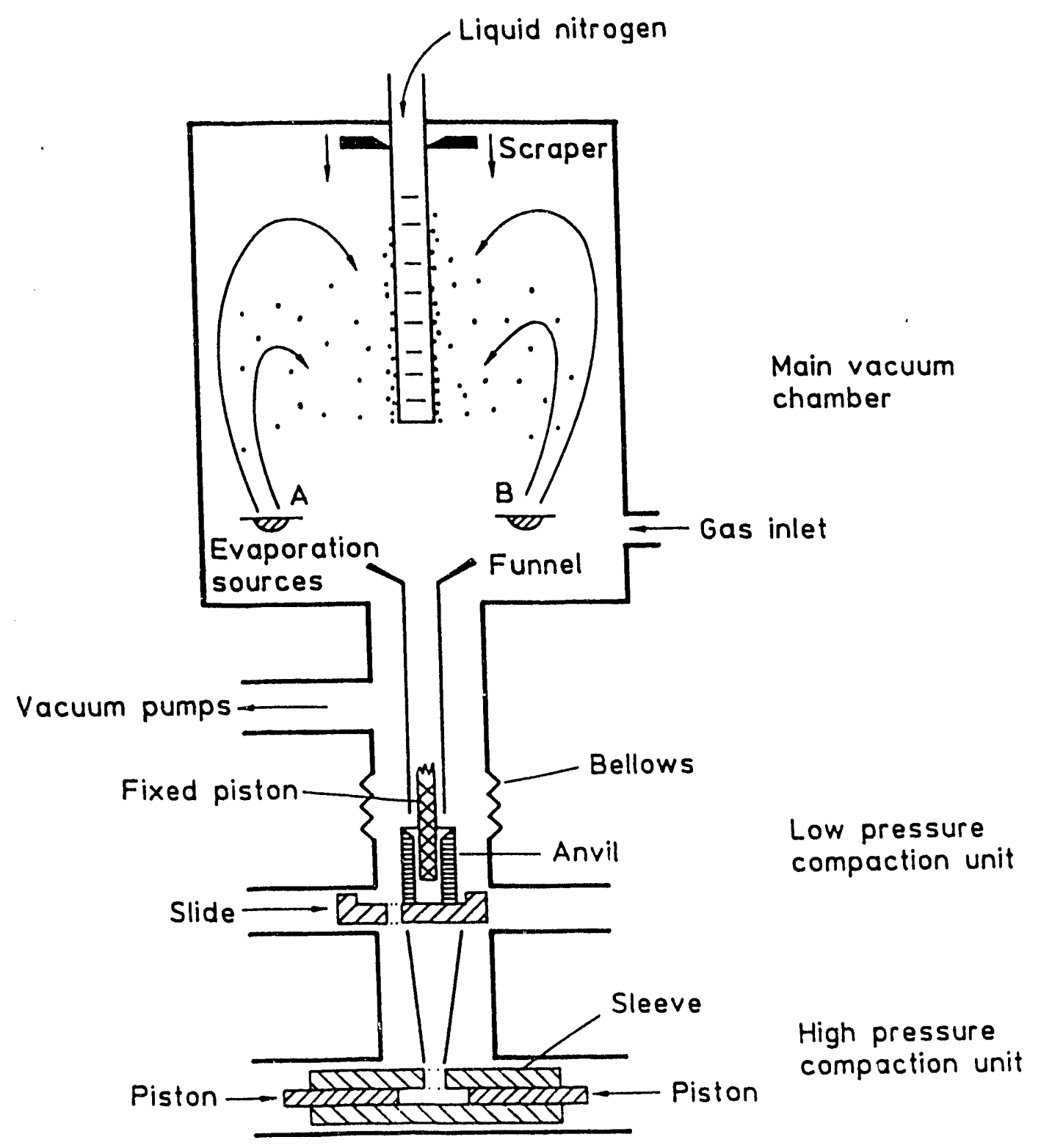

Fig. 1. 


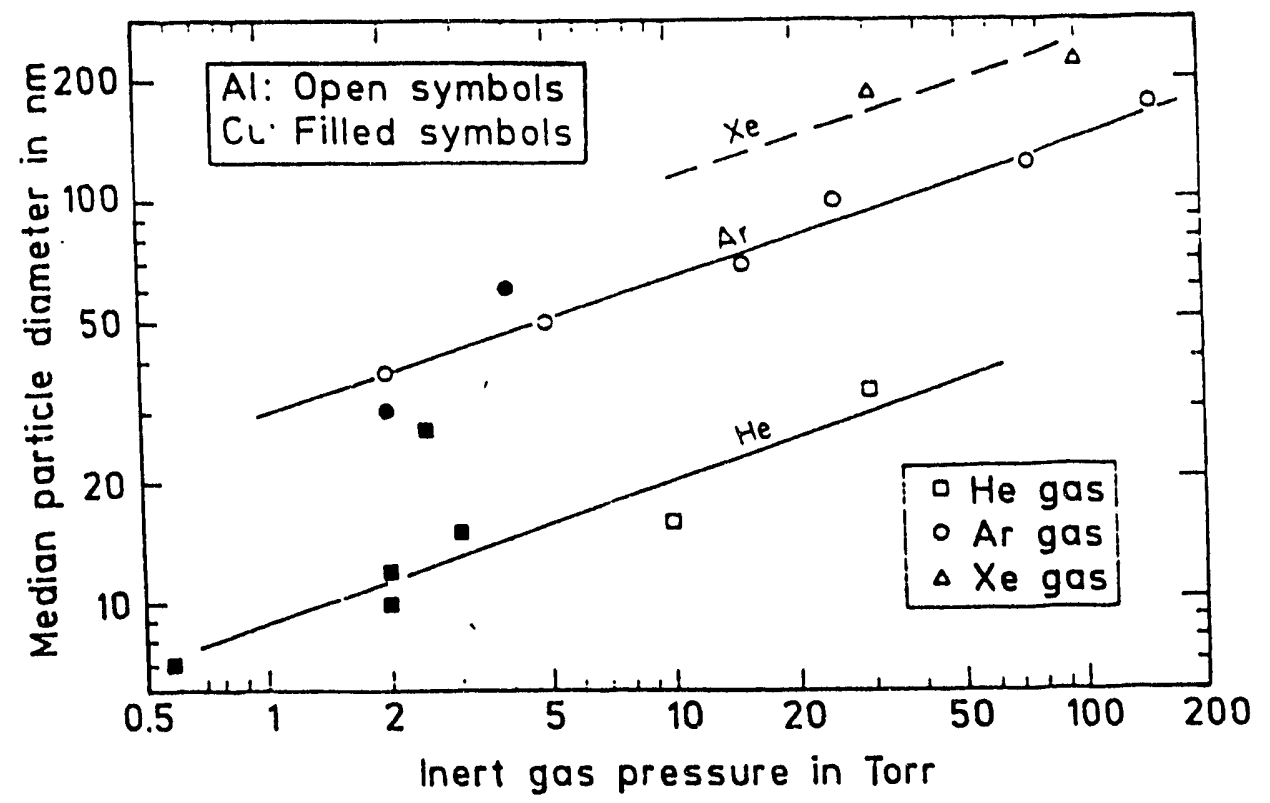

$F_{i g} \cdot 2$

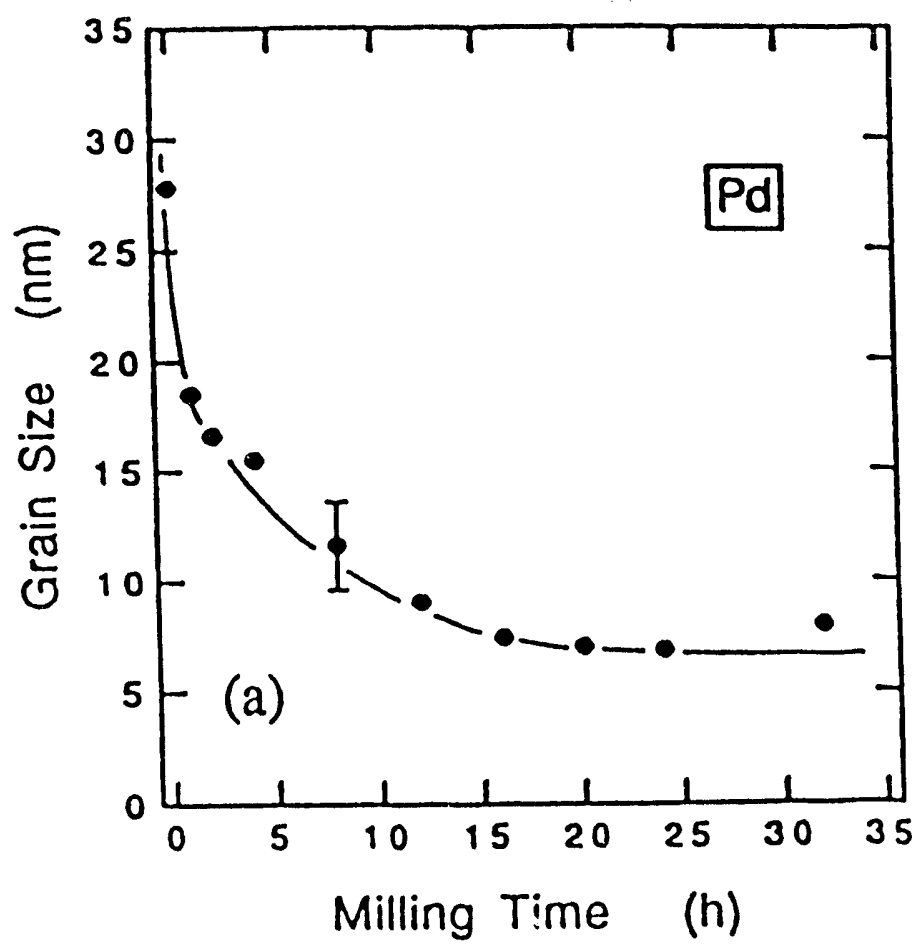

Fig. 3. 


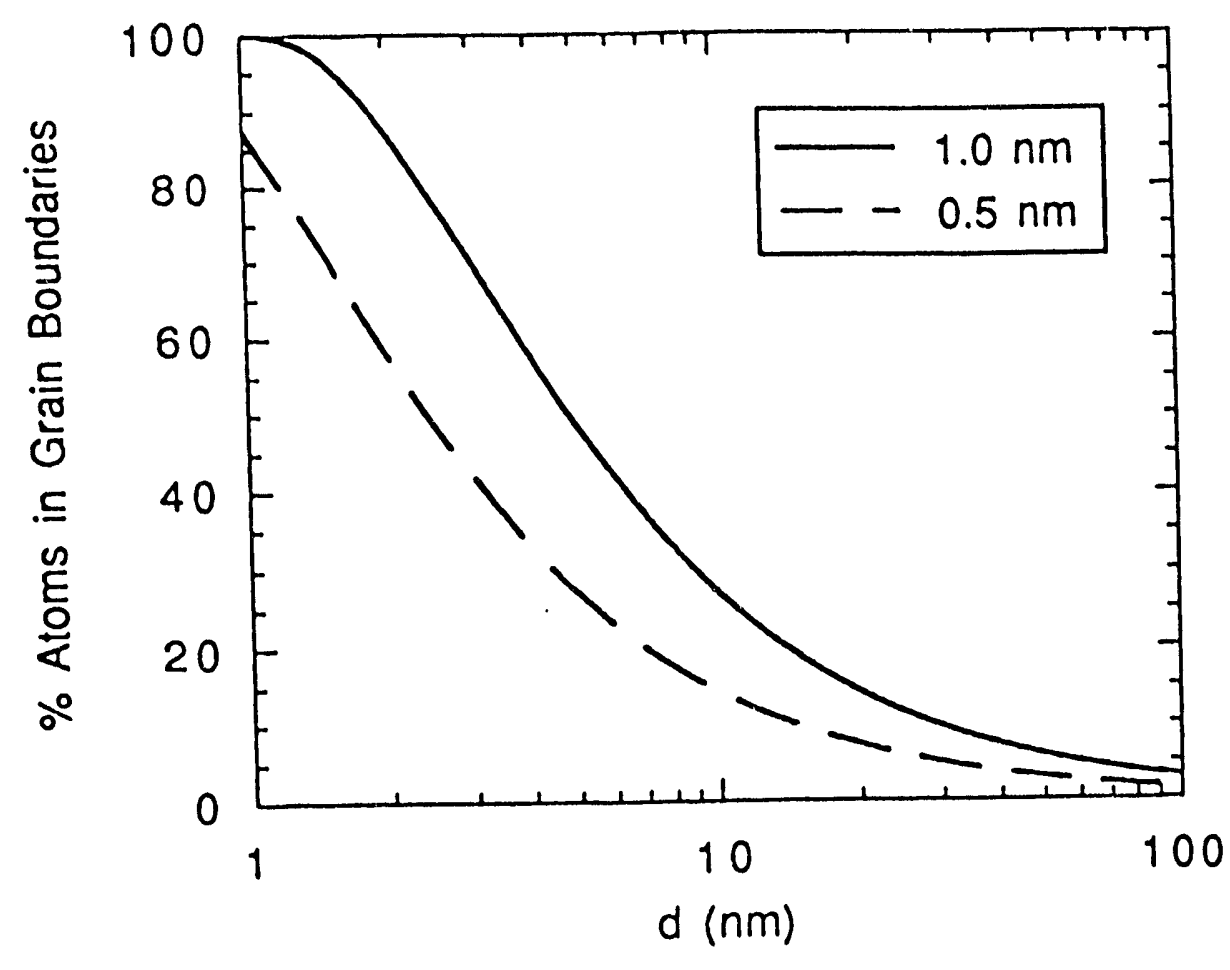

Fig. 4.

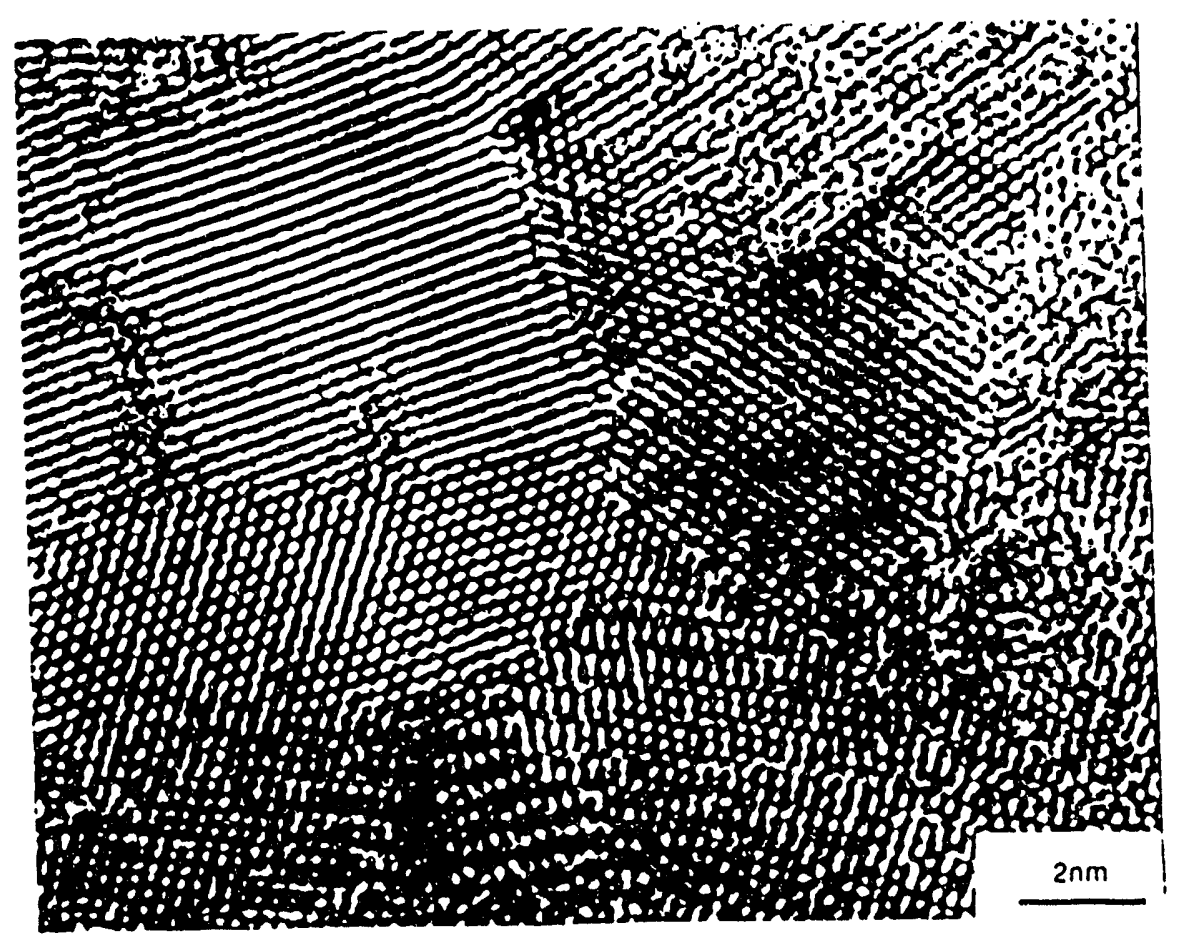

Fig. 5 . 


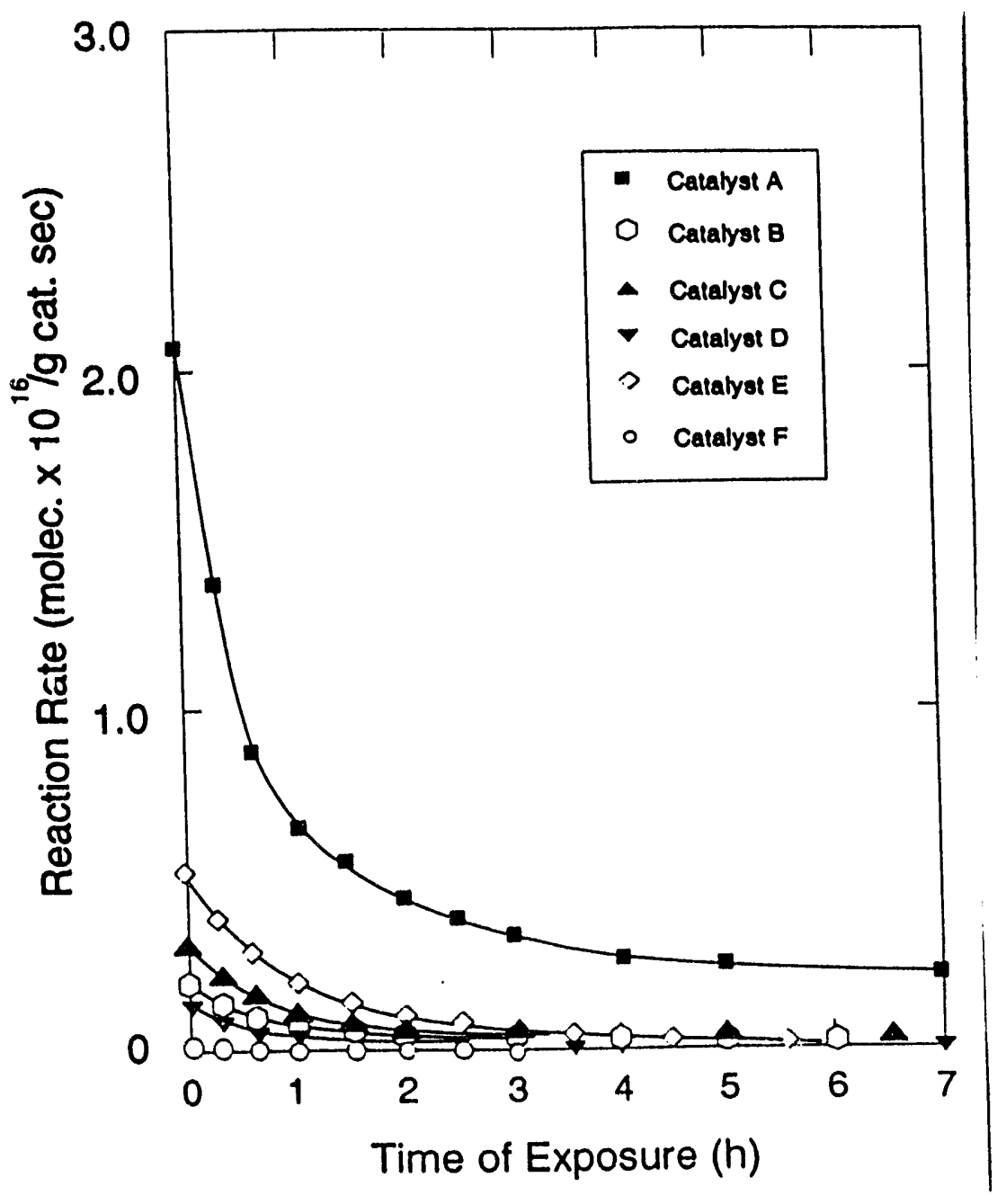

$F$ ig. 6. 


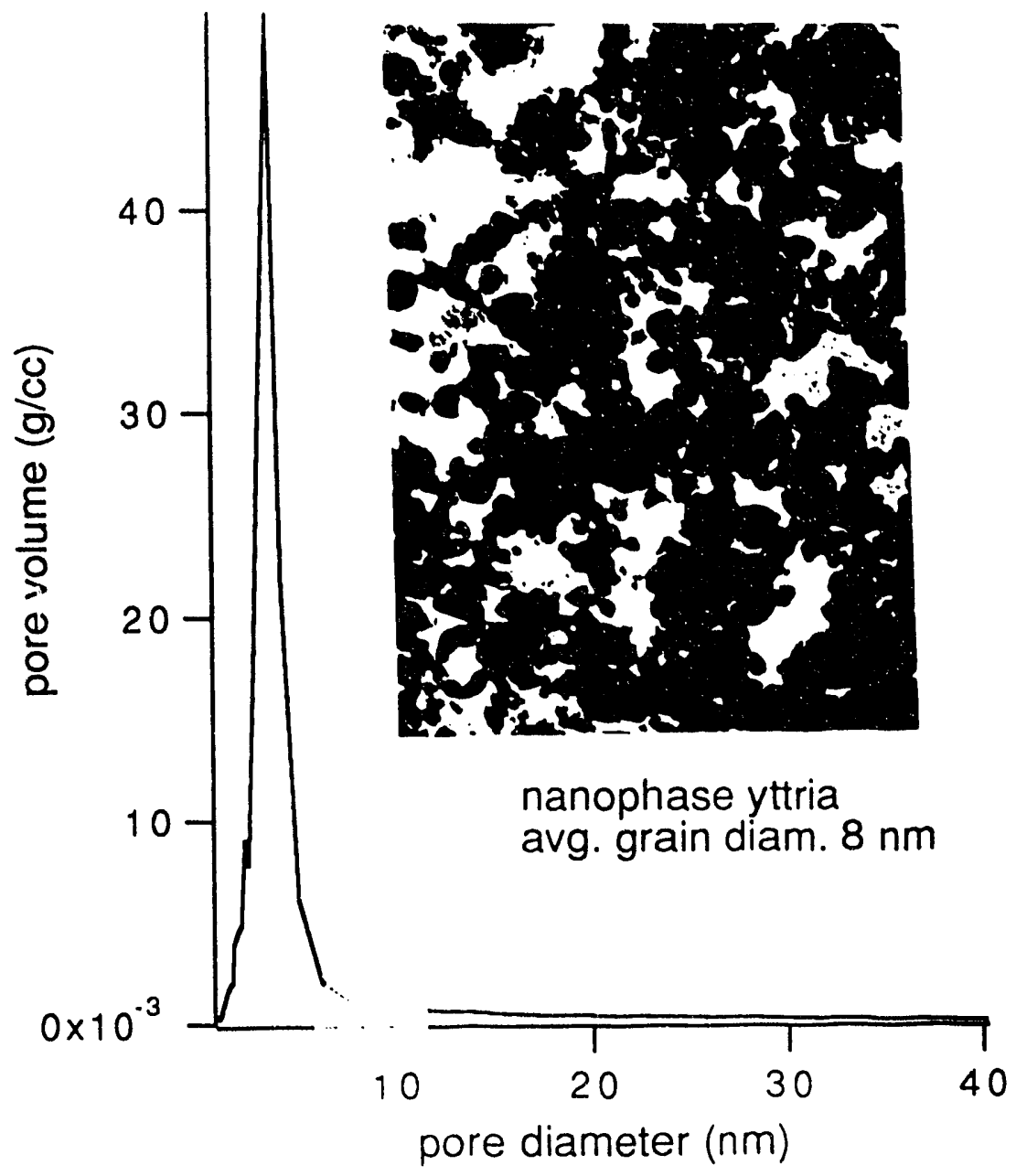

Fig: 7. 


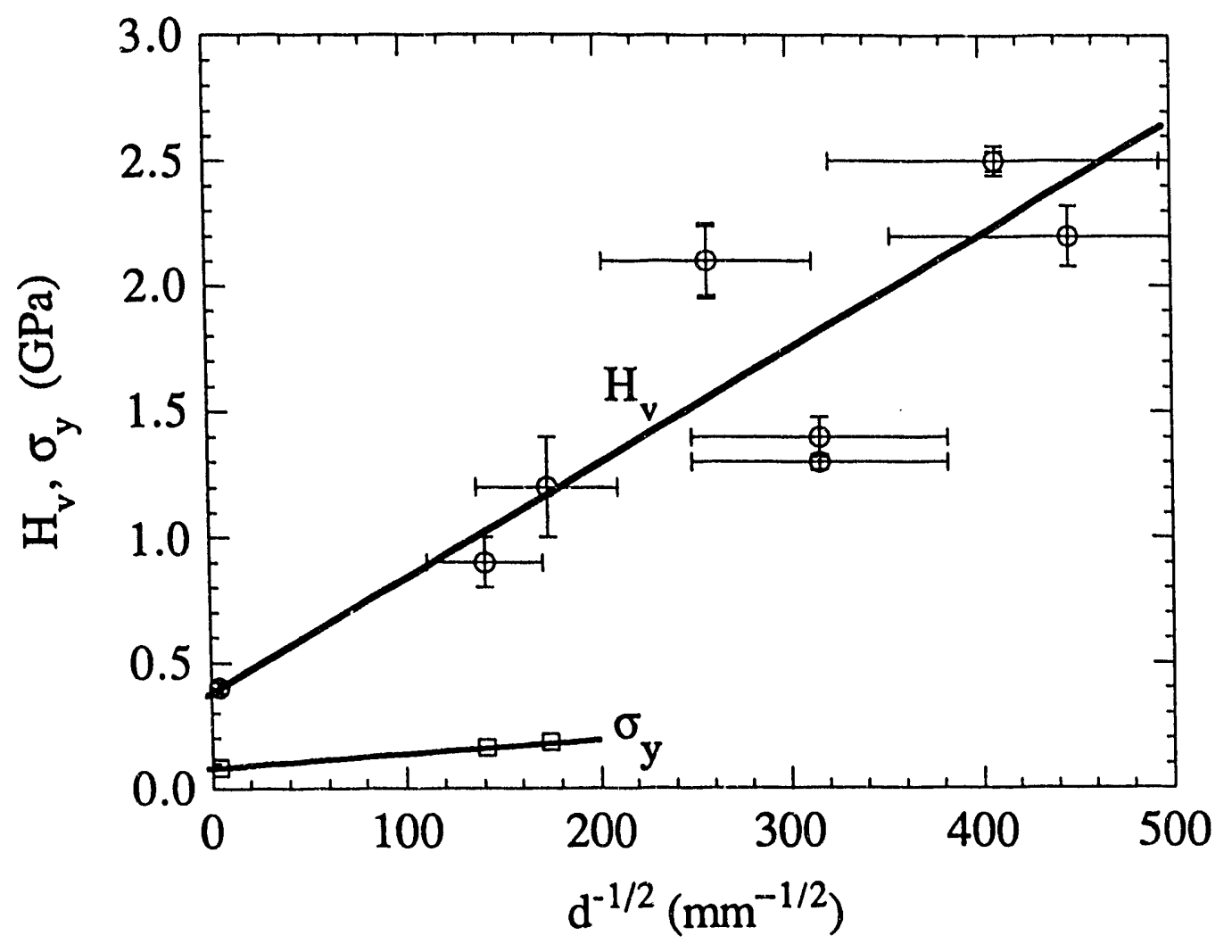

Fig. 8. 


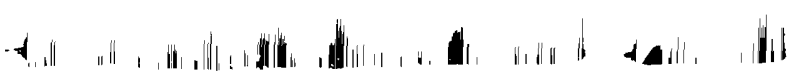

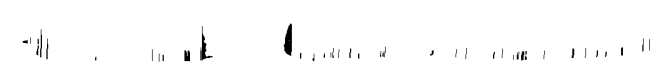

7. $: 8-2-1$
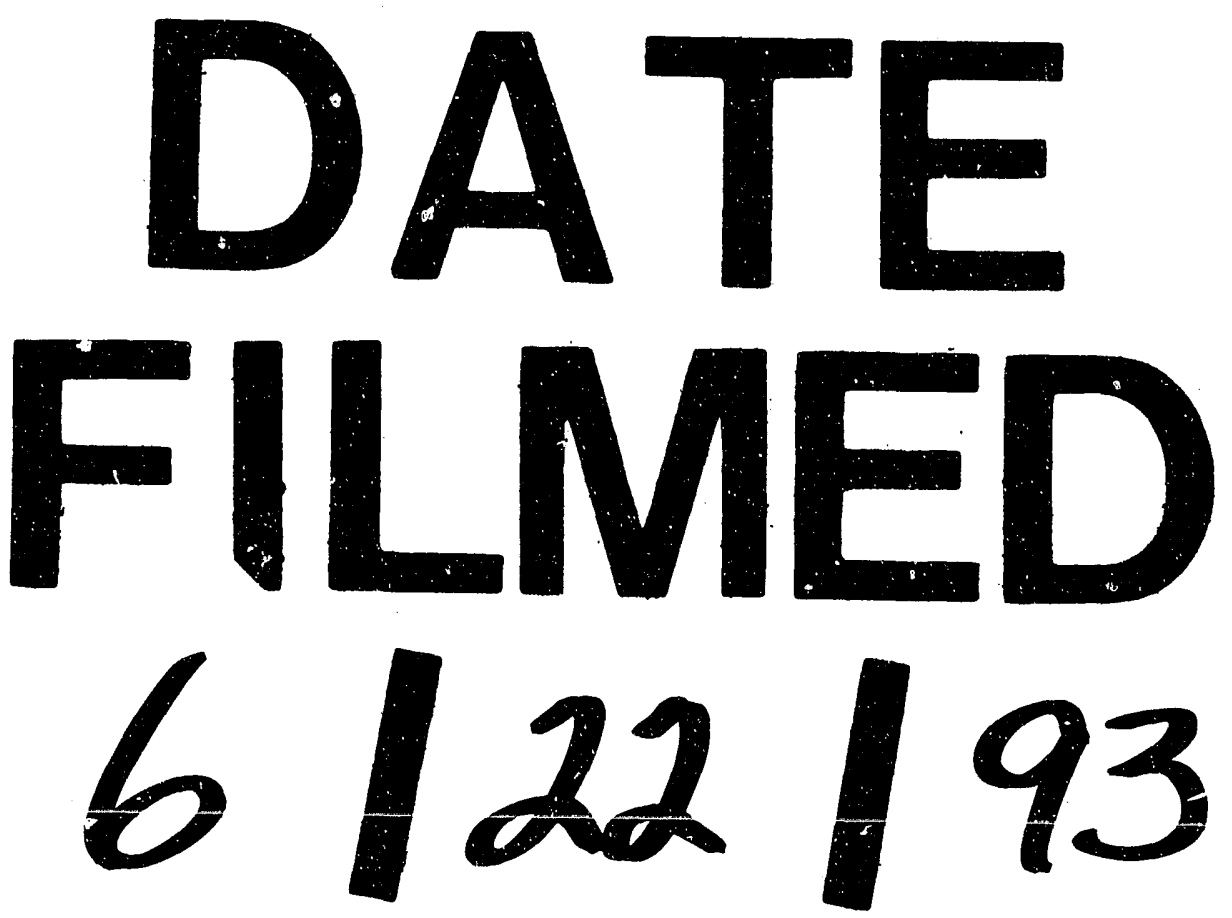
